\title{
VIDEO-ASSISTED THORACOSCOPIC TREATMENT OF SPONTANEOUS PNEUMOTHORAX: TECHNIQUE AND RESULTS OF ONE HUNDRED CASES
}

\author{
Jérôme Mouroux, $\mathrm{MD}^{\mathrm{a}}$ \\ Dan Elkaïm, MD ${ }^{\mathrm{a}}$ \\ Bernard Padovani, MD ${ }^{\mathrm{b}}$ \\ Aline Myx, MD \\ Christophe Perrin, MD ${ }^{c}$ \\ Christine Rotomondo, MD \\ Jean-Michel Chavaillon, $\mathrm{MD}^{\mathrm{d}}$ \\ Bruno Blaive, $\mathrm{MD}^{\mathrm{c}}$ \\ Henri Richelme, $\mathrm{MD}^{\mathrm{a}}$
}

Objective: This article describes the technique and results for an initial series of 100 pneumothoraces treated by video-assisted thoracoscopy. Methods: From May 1991 to November 1994, 97 patients (78 male and 19 female patients) aged $37.2 \pm 17$ years (range 14 to 92 years) underwent video-assisted thoracoscopy for treatment of spontaneous pneumothorax (primary in 75 patients, secondary in 22 patients). Results: The procedure was unilateral in 94 patients and bilateral in three patients (total 100 cases). Pleural bullae were resected with an endoscopic linear stapler; a lung biopsy was performed in the absence of any identifiable lesion. Pleurodesis was achieved by electrocoagulation of the pleura $(n=3)$, "patch" pleurectomy $(n=3)$, subtotal pleurectomy $(n=20)$, or pleural abrasion $(n=74)$, including conversion to standard thoracotomy in five. One of these five patients had primary pneumothorax and four had secondary pneumothorax. There were no postoperative deaths. A complication developed in 10 patients: five patients with a primary pneumothorax (6.6\%) and five with a secondary pneumothorax $(27.7 \%)$. The mean postoperative hospital stay was $8.25 \pm 3.2$ days. Mean follow-up is 30 months (range 7 to 49 months). Pneumothorax recurred in $3 \%$ of patients, all of whom were operated on at the start of our experience. Three percent of the patients had chronic postoperative chest pain, Conclusions: Videoassisted thoracoscopy is a valid alternative to open thoracotomy for the treatment of spontaneous primary pneumothorax. Its role for the management of secondary pneumothorax remains to be defined. In the long term, the efficacy of video-assisted thoracoscopic pleurodesis and surgeon experience should yield the same results as standard operative therapy. (J Thorac Cardiovasc Surg 1996;112:385-91)
$A^{n}$ fter the first thoracoscopy performed in 1910 by Jacobaeus, 1 pneumologists and thoracic surgeons used the technique for many years to explore the pleural cavity. Use for therapeutic procedures was limited, however, and it was not until the development of abdominal video-endoscopic equip-

From the Services de Chirurgie Abdominale et Thoracique, Radiologie, ${ }^{b}$ and Pneumologie et de Réanimation Respiratoire, ${ }^{\mathfrak{C}}$ Hôpital Pasteur, Nice, and the Service de Pneumologie, ${ }^{d}$ Hôpital Général d'Antibes, Antibes, France.

Received for publication August 22, 1995; revisions requested Sept. 25, 1995; revisions received Jan. 23, 1996; accepted for publication Jan. 26, 1996.

Address for reprints: Jérôme Mouroux, MD, Service de Chirurgie Abdominale et Thoracique, Hôpital Pasteur, B.P. 69, 06002 Nice Cedex, France.

Copyright (C) 1996 by Mosby-Year Book, Inc.

$0022-5223 / 96 \$ 5.00+0 \quad \mathbf{1 2 / 1 / 7 2 3 2 3}$ ment for abdominal surgery that thoracoscopic techniques were widely adopted for management of mediastinal and pleuropulmonary disease, ${ }^{2,3}$ with pneumothorax rapidly becoming one of the major indications. ${ }^{4-8}$

We first began using video-assisted thoracoscopy (VATS) in November 1990 for resection of mediastinal cysts and sympathectomies. After the introduction of endoscopic linear staplers allowing peripheral tissue resection with satisfactory hemostasis and control of air leaks, we expanded our indications for VATS to the treatment of pneumothorax. This report describes our experience and results with the method for our first 100 cases of spontaneous pneumothorax.

\section{Patients and methods}

From May 1991 to November 1994, 100 pneumothoraces were operated on by means of VATS in 97 patients. 
Technique. The operation was done with the patient under general anesthesia. A double-lumen endotracheal tube (Carlens tube) permitted single lung ventilation. The side on which the operation was done was usually excluded from the outset to obtain adequate lung collapse. The anesthesiologist monitored lung volume by monopolar ventilation. In case of intraoperative hypoxia, the inspired oxygen fraction was modified from 0.5 to 1 . If this proved insufficient, a bronchial tube was introduced into the ventilating channel of the nonventilated lung and a continuous flow of oxygen $(5 \mathrm{~L} / \mathrm{min})$ was supplied, thereby increasing oxygen saturation by 2 or 3 points.

The patient was placed in a posterolateral thoracotomy position with the surgeon standing behind. A $10 \mathrm{~mm}$ trocar was introduced through the eighth or ninth intercostal space near the midaxillary line for insertion of a 0 -degree endoscope. Two additional ports were then inserted under direct vision: a $12 \mathrm{~mm}$ trocar through the fifth intercostal space on the anterior axillary line, slightly behind the mammary line, and a $12 \mathrm{~mm}$ posterior trocar through the fifth intercostal space, opposite the tip of the scapula. To identify the site of the air leak, we instilled 500 $\mathrm{ml}$ of saline solution during slight pulmonary ventilation (air chamber test). Lesions were resected with an endoscopic linear stapler (Endo-GIA 30, Auto Suture Company Division, United States Surgical Corporation, Norwalk, Conn., or EZ35B, Ethicon Endo-Surgery, Inc., Cincinnati, Ohio).

Pleurodesis was stimulated by one of four techniques: (1) Patch pleurectomy involved grasping the parietal pleura at different sites with a grasping forceps; segments of pleura were excised with scissors or with an electrocoagulating hook knife. (2) Punctiform electrocoagulation of the parietal pleura was done by application of a coagulator hook to multiple sites on the parietal pleura. These two methods were used at the start of our experience but were later abandoned. (3) Pleural abrasion was done by rubbing the pleural surface with a pledget of wide-mesh polyglycolic acid gauze (Davis \& Geck Division, American Home Products, Danbury, Conn., distributed by ERCL, Serquigny, France) attached to the tip of a standard curved dissector. The entire parietal surface was abraded by inserting the dissector directly through the various port sites. (4) Subtotal pleurectomy, from the apex to the fifth or sixth intercostal space, was completed inferiorly by pleural abrasion. Pleurectomy, performed with an electric knife, was delimited by the thoracic artery anteriorly and the sympathetic nerve posteriorly; the two incisions joined at the top of the first rib. Slight abrasion of the pleural zone delimited in this manner facilitated pleural stripping, which was achieved by lifting the pleural flap with the aid of a gauze pledget.

After postoperative lung reinflation, normal saline solution was again instilled to check for air leaks. Two chest tubes (32 Charriere, Sherwood Medical, Tullamore, Ireland) were placed through the anterior and middle port sites; the posterior port site was closed in two layers. The tubes were connected to an aspiration system and negative suction of $-25 \mathrm{~cm} \mathrm{H}_{2} \mathrm{O}$ was applied. The surgical specimens were routinely sent to the histopathology laboratory; certain samples were also examined for bacterial growth.
Postoperative care. The patients were extubated in the operating theater and observed for 2 to 3 hours in the recovery room. Postoperative analgesics (subcutaneous buprenorphine and paracetamol) were adapted to individual requirements. Epidural analgesia was not used.

Data recorded for all patients included a detailed history, the number of episodes of pneumothorax and their primary or secondary nature, treatment modalities, the nature of bullae (site, size, and number [fewer than or more than 5]), the existence of adhesions, the operative time, the number of forceps and Auto Suture loading units used, and the type of pleurodesis. The output and duration of pleural drainage after the surgical procedure, the quantity of analgesics administered during hospitalization, the length of the postoperative hospital stay, mortality, complications, recurrences, and the interval to recurrence were also recorded.

Data analysis. Values were expressed as the mean \pm standard deviation. Data were analyzed by the unpaired $t$ test. Disease variables were analyzed by the $\chi^{2}$ test or, when appropriate, Fisher's exact test. A $p$ value less than 0.05 was considered significant.

\section{Results}

This series included 78 male and 19 female patients aged $37.2 \pm 17$ years (range 14 to 92 years). Sixty-six patients were younger than 40 years old, 31 were smokers ( $21.12 \pm 16.37$ pack-years), and two had human immunodeficiency virus. Four patients had previously undergone thoracotomy for a contralateral pneumothorax, and six patients had been managed by talc insufflation on the side of the pneumothorax operated on by VATS techniques. Seventy patients were examined preoperatively by computed tomographic (CT) scanning; this imaging technique was possible even in those patients requiring maintenance of aspiration drainage during scanning.

Spontaneous pneumothorax was primary in 75 patients (mean age $31.9 \pm 12.2$ years). The causes of secondary spontaneous pneumothorax in the remaining 22 patients (mean age $54.8 \pm 19.6$ years) included emphysema $(n=13)$, Marfan syndrome $(n=1)$, asthma $(n=2)$, lymphangiomatosis $(n=1)$, histiocytosis $\mathrm{X}(n=1)$, cystic mesenchymal hamartoma $(n=1)$, tuberculosis $(n=1)$, and pneumocystosis $(n=2$, including one case associated with an atypical mycobacterial infection).

In 21 cases, VATS was performed because of alternating episodes of pneumothorax. Only the most recently involved side was treated in these patients; the other side was operated on only in case of a new recurrence. Among the 94 patients with unilateral involvement, 23 were operated on after their first episode of pneumothorax (two for associ- 
ated hemothorax, three for personal and professional convenience, and 18 for persistent air leak [ 7 days of pleural drainage] including two after talc pleurodesis). Thirty-two patients were operated on after a second episode of pneumothorax, and 21 patients were treated after three or more episodes.

VATS was unilateral in 94 patients and bilateral in three patients. All procedures were performed by the same surgeon, on the right side in 56 cases and on the left side in 44 cases. Seventy-six patients had focal bullae (Table I); 11 others had diffuse lesions. Twelve patients had pleuropulmonary adhesions ( $8 / 12$ centered on pleural bullae). No gross lesion was detected during exploration or by CT scan in 10 patients.

Pleural bullae were resected by an endoscopic linear stapler. In the absence of any identifiable lesion, a specimen of lung tissue was obtained by biopsy at the apex or the base of an adhesion. In three cases, two staplers were necessary (one device was defective, and more than five loading units were required for the stapler in two cases). One stapler sufficed in all other patients; the mean number of loading units per patient was $2.9 \pm 1.9$.

Pleurodesis was performed by punctiform electrocoagulation in three cases, patch pleurectomy in three cases, subtotal pleurectomy in 20 cases, and pleural abrasion in 74 cases, including five after conversion to standard thoracotomy. The mean operative time was $72.45 \pm 29.4$ minutes (range 45 to 180 minutes).

Four patients with secondary pneumothorax $(18.18 \%)$ required conversion: three because of the volume of the bullae and the quality of the adjacent parenchyma (associated in one case with poor tolerance of lung exclusion), and one because of apical adhesions consecutive to talc pleurodesis. One patient with primary pneumothorax $(1.3 \%)$ required conversion because selective intubation proved impossible. This difference is statistically significant.

The postoperative course is detailed in Table II. No patient required a transfusion and there were no postoperative deaths. A complication developed in 10 patients (Table III). Three of the four patients who had pleural detachment required a second drainage. No significant difference was observed concerning the rate of complications, the duration or output of chest tube drainage, or the dose of analgesic agents administered as a function of the mode of pleurodesis. By contrast, complications were significantly more frequent in patients with secondary pneumothorax than in those with primary pneumothorax $(27.7 \%$ versus $6.6 \%)$ (Table IV).
Table I. Location, size, and number of focal pleural bullae

\begin{tabular}{cc}
\hline & No. \\
\hline Site & 54 \\
Apex & 4 \\
Mediastinum & 7 \\
Apex and mediastinum & 4 \\
Base & 7 \\
Other & \\
Size & 34 \\
$<1 \mathrm{~cm}$ & 28 \\
1 to $3 \mathrm{~cm}$ & 6 \\
3 to $5 \mathrm{~cm}$ & 8 \\
$>5 \mathrm{~cm}$ & \\
Number & 42 \\
$<5$ & 34 \\
$>5$ & \\
\hline
\end{tabular}

All patients in this series were followed up regularly; mean follow-up as of June 1995 was 30 months (range 7 to 49 months). Three patients had a recurrence, but all three had been operated on during the first year of our experience. Two of these recurrences occurred in patients in whom no bullae were identified $(2 / 10,20 \%)$, and the third occurred in one of the 87 patients with visible lesions $(1.5 \%)$. This difference is statistically significant. These recurrences occurred after electrocoagulation $(n=1)$ or pleural abrasion $(n=2) 1,5$, and 6 months after the intervention. All patients underwent a reoperation (one by thoracotomy and two by VATS). Three patients have residual chest pain (two in the submammary region and one at a drain site) after 18 , 35 , and 37 months; two of them take analgesic medications.

\section{Discussion}

Spontaneous pneumothorax is common. Primary (idiopathic) pneumothorax affects young individuals whereas secondary pneumothorax is more common in older patients. ${ }^{9}$ Emphysema is the most frequent cause for secondary pneumothorax $(69 \%$ in our series). A first episode of pneumothorax can usually be managed by simple means such as bed rest, chest tube decompression, and drainage. Refractory recurrent or alternating pneumothorax necessitates a more aggressive approach aimed primarily at achieving pleurodesis. Alternatives to surgical treatment include chemical pleurodesis by administration of a pleural irritant during thoracoscopy: tetracycline,${ }^{10}$ fibrin glue, ${ }^{11}$ kaolin, ${ }^{12}$ and silver nitrate ${ }^{13}$ have all been used. Pure talc is the most commonly used agent in France. Drawbacks of this method 
Table II. Operative course (95 VATS procedures)

\begin{tabular}{|c|c|c|c|c|}
\hline & $\begin{array}{c}\text { VATS } \\
(n=95)\end{array}$ & $\begin{array}{l}V A T S / P A \\
(n=69)\end{array}$ & $\begin{array}{l}\text { VATS/SP } \\
(n=20)\end{array}$ & $\begin{array}{c}\text { VATS/other } \\
\quad(n=6)\end{array}$ \\
\hline Ablation of the first drain & $3.36 \pm 1.2$ days & $3.36 \pm 1.17$ days & $3.22 \pm 0.9$ days & $3.33 \pm 0.5$ days \\
\hline Ablation of the second drain & $5.3 \pm 2$ days & $5.44 \pm 2.1$ days & $4.89 \pm 1.41$ days & $5.16 \pm 0.75$ days \\
\hline Chest tube output & $333.4 \pm 254 \mathrm{ml}$ & $315.8 \pm 240 \mathrm{ml}$ & $367 \pm 206 \mathrm{ml}$ & $245.8 \pm 142.8 \mathrm{ml}$ \\
\hline \multicolumn{5}{|l|}{ Analgesics } \\
\hline Buprenorphine (dose range) & & $\begin{array}{l}0.92 \pm 0.70 \mathrm{mg} \\
(0.3 \text { to } 2.5 \mathrm{mg})\end{array}$ & $\begin{array}{l}1.01 \pm 0.66 \mathrm{mg} \\
(0.3 \text { to } 2.5 \mathrm{mg})\end{array}$ & \\
\hline Paracetamol (dose range) & & $\begin{array}{l}8.24 \pm 4.45 \mathrm{gr} \\
(2.5 \text { to } 15.5 \mathrm{gr})\end{array}$ & $\begin{array}{r}9.97 \pm 3.48 \mathrm{gr} \\
\quad(6 \text { to } 18 \mathrm{gr})\end{array}$ & \\
\hline Postop hospital stay & $8.25 \pm 3.2$ days & $8.2 \pm 3.2$ days & $7.5 \pm 1.5$ days & $9.3 \pm 5.3$ days \\
\hline Complications & 10 & 7 & 2 & 1 \\
\hline
\end{tabular}

VATS, Video-assisted thoracoscopy; $P A$, pleurodesis by pleural abrasion; $S P$, pleurodesis by subtotal pleurectomy; other, pleurodesis by electrocoagulation or patch pleurectomy.

Table III. Postoperative complications

\begin{tabular}{lllcc}
\hline & $\begin{array}{l}\text { VATS/PA } \\
(n=69)\end{array}$ & $\begin{array}{l}\text { VATS/SP } \\
(n=20)\end{array}$ & $\begin{array}{c}\text { VATS/other } \\
(n=6)\end{array}$ & $\begin{array}{c}\text { Conversion/PA } \\
(n=5)\end{array}$ \\
\hline Prolonged air leak $(>7$ days $)$ & 3 & - & - & - \\
Pleural detachment & 3 & - & 1 & - \\
Abscess (drain site) & 1 & - & - & - \\
Bronchopneumonia & - & 1 & - & - \\
Apical hematoma & - & $2(10 \%)$ & $1(16.6 \%)$ & 0 \\
Total $(10)$ & $7(11.6 \%)$ & &
\end{tabular}

VATS, video-assisted thoracoscopy; $P A$, pleurodesis by pleural abrasion; $S P$, pleurodesis by subtotal pleurectomy; other, pleurodesis by electrocoagulation or patch pleurectomy.

Table IV. Complications as a function of the type of pneumothorax

\begin{tabular}{lll}
\hline & $\begin{array}{c}\text { Primary } \\
\text { pneumothorax } \\
(n=74)^{*}\end{array}$ & $\begin{array}{c}\text { Secondary } \\
\text { pneumothorax } \\
(n=18)^{*}\end{array}$ \\
\hline $\begin{array}{c}\text { Prolonged air leak } \\
\quad>7 \text { days })\end{array}$ & - & 3 \\
$\begin{array}{l}\text { Pleural detachment } \\
\text { Abscess (drain site })\end{array}$ & 4 & - \\
Bronchopneumonia & - & - \\
Apical hematoma & - & 1 \\
Total (10) & $5(6.75 \%)$ & 1 \\
& & $5(27.7 \%)$ \\
\end{tabular}

SSD, Statistically significant difference.

${ }^{*}$ Excluding conversions.

include the fact that it does not treat parenchymal lesions and involves a risk of pleural exudate and foreign body reaction. ${ }^{14,15}$ Recurrence has been reported in $5 \%$ to $15 \%$ of cases. ${ }^{16-20}$

Surgical management of pneumothorax by thoracotomy is aimed at treating parenchymal lesions and achieving pleurodesis by abrasion or pleurectomy. Pleural abrasion was first described in 1925 by Lilienthal, ${ }^{21}$ whereas surgical treatment of pneumo- thorax is relatively recent. Gaensler ${ }^{22}$ first proposed pleurectomy in 1956, and Clagett ${ }^{23}$ recommended pleural abrasion in 1968.

VATS was first used to treat pneumothorax in 1990 by Levi and associates, ${ }^{4}$ who performed pleurectomy through a 2 to $3 \mathrm{~cm}$ posterior incision with the aid of VATS control. Several subsequent publications confirmed the feasibility of the method and described pleurectomy or pleural abrasion done through an intrapleural approach. ${ }^{6,7,24-27}$ The introduction of endoscopic staplers permitted resection of bullae with satisfactory control of air leaks and hemostasis of tissue margins. ${ }^{28}$ These small series were generally characterized by an absence of mortality and low morbidity, and most authors reported a reduction in postoperative pain and a shorter hospital stay. However, the long-term efficacy of the method remained questionable owing to the limited follow-up.

We first began treating pneumothorax by VATS in May 1991, and this disease is currently our main indication for VATS (35\% of all patients we have operated on to date by this technique). Although the majority of our patients underwent examination by CT scan before the operation, the value of systematic scanning can be debated. Several authors have 
emphasized the importance of CT for etiologic diagnosis of spontaneous pneumothorax. ${ }^{29,}{ }^{30}$ In addition, high-resolution CT scanning permits excellent evaluation of the lung parenchyma. ${ }^{31}$ In our study, however, the data provided by CT did not influence management. We thus currently advocate CT only when the initial clinical etiologic workup leaves a doubt as to the secondary or primary nature of the pneumothorax and for assessment of the extent of lesions in patients with emphysema.

VATS requires familiarity with conventional surgical procedures to correctly explore the chest cavity and evaluate the quality of the lung parenchyma. Selective intubation is indispensable, as is the possibility for ventilatory exclusion during the operation. Along with these requirements common to all VATS procedures, use of the technique to treat pneumothorax must take into account the size of bullae and the quality of the parenchyma.

Proper port site placement is essential for VATS; triangulation permits full access to all zones and eliminates the need to "criss-cross" instruments. Selection of the appropriate intercostal spaces for port placement must be adapted to the subject's morphologic characteristics; the distances between ports must be increased for longilineal patients. Lesions are best resected with an endoscopic linear stapler that ensures satisfactory control of air leaks and tissue hemostasis. We prefer 30 or $35 \mathrm{~mm}$ staplers, which have several advantages over longer devices: they limit intercostal trauma, are easier to manipulate, especially in patients with a narrow thorax, and permit better control of tissue resection.

Pleural abrasion is our preferred method for pleurodesis. The zones to be abraded can be reached by inserting long conventional surgical instruments such as dissectors via the various port sites. We reserve pleurectomy for certain types of pneumothorax (pneumocystosis in patients with human immunodeficiency virus, diffuse lesions) or recurrence after talc pleurodesis. When subtotal pleurectomy is planned, prior abrasion of the parietal pleura to be resected facilitates stripping and appears to reduce bleeding (see Table II).

There were no intraoperative or postoperative deaths. The most frequent postoperative complications (prolonged air leak lasting more than 7 days, partial pleural detachment) were similar to those observed after conventional operations. There were no complications specific to the VATS technique. Although morbidity was low after treatment of primary pneumothorax $(6.6 \%)$, it was higher for patients with secondary pneumothorax (27.7\%), who constitute a high-risk group. ${ }^{32}$ After thoracotomy, Tanaka and associates ${ }^{9}$ reported a morbidity of $37 \%$ and a mortality of $4 \%$. Although our results are more favorable, it is premature to affirm the superiority of VATS, especially inasmuch as we had to convert the operation four times in this group of patients.

Ever since we started using VATS, we have continued to use the same principles of drainage as after thoracotomy. Two drains are inserted systematically, and they are removed successively at a minimum interval of 24 hours. We consider aspiration drainage an integral part of the treatment because it promotes pleural symphysis.

In the literature, the duration of postoperative drainage is variable. Inderbitzi and coworkers ${ }^{7}$ reported a mean duration of 1 day, Radberg and colleagues $^{33} 4$ days, and Bernard and associates ${ }^{34}$ $5 \pm 2$ days. These variations appear attributable more to the number of drains used and to the habits of the surgical teams than to the method itself.

Although all of our patients had postoperative chest pain (dysesthesia), mainly at the drain sites or in the submammary region, the quantities of analgesic drugs used seem to confirm the reduction in postoperative discomfort previously described in the literature. ${ }^{33-35}$ This improvement was confirmed in the four patients who had previously undergone thoracotomy. The problem of chronic postoperative pain has not been totally solved by VATS, because $3 \%$ of our patients have residual chest pain that sometimes requires use of analgesic medications. As emphasized by several authors, intercostal trauma is undoubtedly one of the causes.

Our long-term recurrence rate is 3\%. These recurrences occurred early after the intervention. Like Naunheim's group, ${ }^{36}$ we found that these recurrences were more frequent in patients in whom no bullae were identified. Our recurrence rate is comparable with those reported in the literature after thoracoscopy, which vary from $2.7 \%$ to $4.7 \%$. $7,24,36$ These results are less favorable than those obtained after thoracotomy, after which the recurrence rate varies from 05 to $2 \% .^{37-42}$ In our opinion, these results should not cast doubt on the validity of the method because they were attributable to the learning curve, as with any new method. None of the patients operated on starting in 1992 has had a recurrence.

In conclusion, VATS appears to be a valid alternative to open thoracotomy for the treatment of 
spontaneous primary pneumothorax: exploration is just as good as with axillary thoracotomy, if not better, the technique is generally simple, cosmetic prejudice is minimal, and postoperative comfort is satisfactory. However, our experience does not allow us to affirm any significant gain in terms of the duration of postoperative drainage or hospitalization. At long term, with increasing surgeon experience, results should equal those obtained by thoracotomy. The role and the results of VATS for the treatment of secondary pneumothorax merit additional evaluation.

We thank Nancy Rameau for translation of the manuscript.

\section{REFERENCES}

1. Jacobeus HC. Ueber die möglichkeit die zystoskopie bei untersuchung seroser hohlungen Anzuwenden. Munch Med Wochenschr 1910;57:2090-2.

2. Hazelrigg SR, Nunchuck SK, LoCicero J, The Video-Assisted Thoracic Surgery Study Group. Video-assisted thoracic surgery Study Group data. Ann Thorac Surg 1993;56:103944.

3. Mouroux J, Richelme H. Surgical endoscopy in thoracic surgery. Biomed Pharmacother 1992;46:139-41.

4. Levi JF, Kleinmann P, Riquet M, Debesse B. Percutaneous parietal pleurectomy for recurrent spontaneous pneumothorax. Lancet 1990;336:1577-8.

5. Kleinmann P, Levi JF, Debesse B. La pleurectomie pariétale percutanée par vidéo-endoscopie. Le traitement moderne du pneumothorax spontané récidivant. Rev Mal Respir 1991;8: $459-62$.

6. Mouroux J, Benchimol D, Bernard JL, et al. Traitement chirurgical du pneumothorax par vidéo-thoracoscopie. Presse Med 1992;21:1079-82.

7. Inderbitzi RGC, Furrer M, Striffeler H, Althaus U. Thoracoscopic pleurectomy for treatment of complicated spontaneous pneumothorax. J Thorac Cardiovasc Surg 1993;105: 84-8.

8. Nathanson LK, Shimi SM, Wood RAB, Cuschieri A. Videothoracoscopic ligation of bulla and pleurectomy for spontaneous pneumothorax. Ann Thorac Surg 1991;52:316-9.

9. Tanaka $F$, Itoh $M$, Esaki $H$, Isobe J, Ueno $Y$, Inoue $R$. Secondary spontaneous pneumothorax. Ann Thorac Surg 1993;55:372-6.

10. Almind M, Lange $P$, Viskum K. Spontaneous pneumothorax: comparison of simple drainage, talc pleurodesis, and tetracycline pleurodesis. Thorax 1989;44:627-30.

11. Guerin JC, Vanderschueren RG. Traitement des pneumothorax récidivants par application de colle de fibrine sous endoscopie. Rev Mal Respir 1989;6:443-5.

12. Joynt GHC, Laird RC. Treatment of spontaneous pneumothorax with kaolin. Dis Chest 1958;34:514-20.

13. Andersen J, Nissen H. Results of silver nitrate pleurodesis in spontaneous pneumothorax. Dis Chest 1968;54:62-5.

14. Bouchama A, Chastre J, Gaudichet A, Soler P, Gibert C. Acute pneumonitis with bilateral pleural effusion after talc pleurodesis. Chest 1984;86:795-7.
15. Rinaldo JE, Owens GR, Rogers RM. Adult respiratory distress syndrome following intrapleural instillation of talc. $J$ Thorac Cardiovasc Surg 1983;85:523-6.

16. Gillet-Juvin K, Guerin JC. Le talcage sous thoracoscopie des pneumothorax par rupture de bulles d'emphys me. Etude de 71 cas. Rev Mal Respir 1991;8:289-93.

17. Givel JCL, Steinhäuslin $\mathrm{CH}$, Leueberger $\mathrm{PH}$, Besson A. Pneumothorax spontané: étude d'un collectif médico-chirurgical. Med Hyg 1984;42:2682-8.

18. Guérin JC, Champel F, Biron E, Kalb JC. Talcage pleural par thoracoscopie dans le traitement du pneumothorax. Etude d'une série de 109 cas traités en 3 ans. Rev Mal Respir 1985;2:25-9.

19. Daniel TM, Tribble CG, Rodgers BM. Thoracoscopy and talc poudrage for pneumothoraces and effusions. Ann Thorac Surg 1990;50:186-9.

20. Boutin C. La symphyse pleurale par talcage sous thoracoscopie. Rev Mal Respir 1989;6:91-3.

21. Lilienthal M. Thoracic surgery. Philadelphia: WB Saunders, 1926:1962.

22. Gaensler EA. Parietal pleurectomy for recurrent spontaneous pneumothorax. Surg Gynecol Obstet 1956;102:293308.

23. Clagett OT. The management of spontaneous pneumothorax. J Thorac Cardiovasc Surg 1968;55:761-2.

24. Yamaguchi A, Shinonaga M, Tatebe S, Souma T, Tsuchida M, Saito A. Thoracoscopic stapled bullectomy supported by suturing. Ann Thorac Surg 1993;56:691-3.

25. Melvin WS, Krasna MJ, Laughlin JS. Thoracoscopic management of spontaneous pneumothorax. Chest 1992;102: $1875-6$.

26. Cannon BW, Vierra MA, Cannon A. Thoracoscopy for spontaneous pneumothorax. Ann Thorac Surg 1993;56:686-7.

27. Takeno Y. Thoracoscopic treatment of spontaneous pneumothorax. Ann Thorac Surg 1993;56:688-90.

28. Krasna MJ, Nazem A. Thoracoscopic lung resection: use of a new endoscopic linear stapler. Surg Laparosc Endosc 1991; 1:248-50.

29. Lesur O, Delorme N, Fromaget JM, Bernadac P, Polu JM. Computed tomography in the etiologic assessment of idiopathic spontaneous pneumothorax. Chest 1990;98:341-7.

30. Warner BW, Bailey WW, Shipley RT. Value of computed tomography of the lung in the management of primary spontaneous pneumothorax. Am J Surg 1991;162:39-42.

31. Stern EJ, Frank MS. CT of the lung in patients with pulmonary emphysema: diagnosis, quantification and correlation with pathologic and physiologic findings. AJR Am J Roentgenol 1994;162:791-8.

32. Shields TW, Oilschlager GA. Spontaneous pneumothorax in patients 40 years of age or older. Ann Thorac Surg 1966;2: $377-83$.

33. Radberg G, Dernevik L, Svanvik J, Thune A. A comparative retrospective study of thoracoscopy versus thoracotomy for the treatment of spontaneous pneumothorax. Surg Laparosc Endosc 1995:5:90-3.

34. Bernard A, Bélichard C, Goudet P, Lombard JN, Viard H. Pneumothorax spontané. Comparaison de la thoracoscopie et de la thoracotomie. Rev Mal Respir 1993;10:433-6.

35. Landreneau RJ, Hazelrigg SR, Mack MJ, et al. Postoperative pain-related morbidity: video-assisted thoracic surgery versus thoracotomy. Ann Thorac Surg 1993;56:1285-9.

36. Naunheim KS, Mack MJ, Hazelrigg SR, et al. Safety and 
efficacy of video-assisted thoracic surgical techniques for treatment of spontaneous pneumothorax. $\mathrm{J}$ Thorac Cardiovasc Surg 1995;109:1198-204.

37. Deslauriers J, Beaulieu M, Després JP, et al. Transaxillary pleurectomy for treatment of spontaneous pneumothorax. Ann Thorac Surg 1980;30:569-74.

38. Maggi G, Ardissone F, Olivario A, Ruffini E, Cianci R. Pleural abrasion in treatment of recurrent or persistent spontaneous pneumothorax: results of 94 consecutive cases. Int Surg 1992;77:99-101.

39. Gamondes JP, Wiesendanger T, Bouvier H, Caillet B, Brune
J. Pneumothorax spontané et récidivant du sujet jeune. Traitement par pleurectomie apicale bilatérale en un seul temps par voie axillaire. Presse Med 1987:16:423-6.

41. Thomas P, Lemee F, Le Hors $H$, et al. Résultats du traitement chirurgical des pneumothorax persistants ou récidivants. Ann Chir: Chir Thorac Cardiovasc 1993;47: 136-40.

42. Dumont P, Nebia A, Roeslin N, Massard G, Wilhm JM, Morand G. Traitement chirurgical du pneumothorax. Etude d'une série de 400 cas. Ann Chir: Chir Thorac Cardiovasc 1995;49:235-40. 